\title{
Privilégios: Relato de uma Trajetória Acadêmica*
}

\author{
Carlos Hasenbalg
}

\section{José Maurício Domingues}

$\mathrm{E}$ stamos aqui para a aula inaugural do professor Carlos Hasenbalg que, lamentamos, nos deixou por Buenos Aires há pouco mais de um ano. Mas como insistimos que ele não vá embora, resolvemos que ele tinha, pelo menos, que voltar agora, para não nos deixar demasiadamente saudosos.

Carlos tem uma trajetória nas ciências sociais brasileiras absolutamente central, e eu tive - já que estamos falando de privilégios - o privilégio de ser seu aluno. Em meados dos anos 1980, quando fiz o mestrado no Instituto Universitário de Pesquisas do Rio de Janeiro (Iuperj), foi ele quem me introduziu a questão racial de forma muito direta, incisiva, como certamente fez com tantos leitores, pesquisadores, estudantes, ao longo de uma carreira produtiva, aqui no Iuperj, e também em outros locais por onde passou.

Agradeço enormemente a presença dele e o fato de ter aceitado o convite, feito em seguida a uma homenagem prestada a ele na Associação Nacional de Pós-Graduação e Pesquisa em Ciências Sociais (Anpocs), há cerca de um ano e meio, e renovada em função da medalha do Mérito Científico, concedida pelo Ministério da Ciência e Tecnologia.

\footnotetext{
* Aula Magna proferida por Carlos Hasenbalg no dia 21 de maio de 2007 no antigo Instituto Universitário de Pesquisas do Rio de Janeiro (Iuperj), atual Instituto de Estudos Sociais e Políticos da Universidade do Estado do Rio de Janeiro (IESP-UERJ).
}

DADOS - Revista de Ciências Sociais, Rio de Janeiro, vol. 57, noำ 2014, pp. 905 a 917. 
Esse conjunto de fatores, a homenagem, a medalha e tudo o que nos ensinou durante muitos anos, foi a motivação imediata para convidá-lo a vir dessa vez. E como foi apenas a motivação imediata, posso garantir que Carlos não escapará de convites futuros para voltar aqui em nossa Casa. Dito isto, passo a palavra a ele, e agradeço, também, a presença de todos neste momento.

\section{Carlos Hasenbalg}

Quero agradecer muito à congregação e à diretoria do Iuperj pelo convite para dar esta aula, que primeiro chamaram de inaugural, e depois de Magna, como pude constatar hoje. Quando recebi o convite, fiquei pensando sobre o que ia dizer, e decidi falar de algo que eu conheço razoavelmente bem: a minha vida acadêmica, esperando que não tomem isto como um sinal de egocentrismo. Falarei um pouco dessa minha trajetória. Os privilégios se referem aos que tive na minha vida de estudante, e como profissional já formado, incluindo quase 40 anos de trabalho nesta Instituição. Seguirei as minhas notas, porque não confio quase nada - na minha memória.

Esses privilégios começaram no meu ingresso no Departamento de Sociologia da Universidade de Buenos Aires (UBA), em 1961. Fui da quinta turma; o departamento tinha sido criado em 1957 e este ano está completando 50 anos. Nos anos 1960, o Departamento de Sociologia da Universidade de Buenos Aires, criação de Gino Germani com apoio de José Luis Romero, passou por sua época de ouro; eram os anos iniciais, mas foi uma época de ouro. Foi, junto com os departamentos da Universidade de São Paulo (USP) e da UNAM (Universidad Nacional Autónoma de México) e o Colégio de México, um dos centros mais importantes da Sociologia latino-americana da época.

Entre os mestres de maior destaque que tive, posso mencionar o próprio Gino Germani, que foi o pioneiro da Sociologia na Argentina; o historiador José Luis Romero, que acabei de citar, grande medievalista, e que tinha ao seu cargo a cátedra de História Social Geral; Jorge Graciarena, que trabalhava com Sociologia do Desenvolvimento e com Sociologia Política; Túlio Halperin Donghi, que muitos de vocês conhecem. Fiz com ele três disciplinas de História Social Argentina. Gregório Klimowsky, epistemólogo, colaborou mais tarde com o Ernesto Sábato no relatório Nunca Mais, sobre os desaparecidos da última ditadura na Argentina, e hoje é professor emérito da UBA. Outro 
grande professor que tive foi Horacio Giberti, um engenheiro agrônomo que ministrava uma disciplina fantástica, na qual aprendi muito, que era Geografia Econômica da Argentina. Giberti, hoje, também é professor emérito da UBA. Além de Torcuato Di Tella e outros muito bons mestres, que não menciono aqui para não abusar.

O sonho acabou pelas mãos de um general de poucas luzes, de nome Juan Carlos Ongania, que deu um golpe em junho de 1966, desmantelou a universidade e, em particular, a área de Ciências Sociais, no país inteiro, mas, principalmente, na Universidade de Buenos Aires.

Tive a sorte, ou, de novo, o privilégio, de ser recrutado por Gláucio Soares, então diretor da Flacso (Facultad Latinoamericana de Ciencias Sociales), para fazer a pós-graduação em Santiago do Chile, em 1966 e 1967. Na Flacso, fui submetido a outra onda de grandes mestres. Fernando Henrique Cardoso e Enzo Faletto tinham acabado, ou estavam acabando, o livro Dependencia y Desarrollo en América Latina, um dos principais livros da literatura sociológica dos anos 1960 e 1970.

Com Fernando Henrique fiz um curso sobre O Capital, que podia, talvez, ter o nome de um livro de uma conhecida marxista althusseriana chilena, Marta Harnecker, chamado Para Leer El Capital. Também foram professores nessa época, na Flacso, Alain Touraine, Johan Galtung e Manuel Castells, menino prodígio da Sociologia, que todos vocês conhecem. Ele nasceu no mesmo ano que eu, 1942, tinha sido discípulo de Touraine e já era professor da Universidade de Paris. Nessa época, Castells, com vinte e poucos anos, nos visitou na Flacso; trabalhava, então, com Movimentos Sociais Urbanos, com Sociologia Urbana, antes de ingressar no tema da sociedade em rede, da sociedade da informação, que concluiu com a famosa trilogia.

Dada a situação na Argentina, em 1967 vim parar no Iuperj por indicação de dois colegas e amigos brasileiros, Vilmar Faria e Carlos Estevam Martins, e aqui fiquei até dezembro de 2005, quando decidi me aposentar.

A última etapa de estudante foi como doutorando em Berkeley, entre 1970 e 1972. Por esses anos, um novo privilégio: o Departamento de Sociologia de Berkeley era o no 1 dos departamentos de Sociologia dos Estados Unidos. Quero aqui destacar um aspecto: meu ingresso no tema das relações raciais se deu nessa época de permanência em Berkeley, e não nos meus três primeiros anos no Brasil, no Iuperj. Vale a 


\section{Carlos Hasenbalg}

pena lembrar que o início dos anos 1970 foi de alta efervescência política nos Estados Unidos, Europa, na França de 1968 etc. - efervescência política que começou em 1968 e que continuou nos primeiros anos da década de 1970 nos Estados Unidos. Grandes mobilizações contra a guerra do Vietnã; ápice das atividades dos Panteras Negras, cujo epicentro estava na cidade de Oakland, vizinha a Berkeley; o movimento de trabalhadores rurais de origem mexicana liderado por César Chávez; e o início da construção do movimento dos chicanos, por um lado, e do movimento pan-asiático.

Robert Blauner, meu orientador de tese, publicou, em 1972, um livro chamado Racial Oppression in America, que era uma codificação acadêmica da teoria do colonialismo interno inspirada em pensamentos do movimento negro americano e de outras minorias raciais.

O livro de Blauner, muito interessante, fazia uma analogia entre as minorias raciais dos Estados Unidos e o colonialismo no Terceiro Mundo. Minha crítica ao livro é que o desfecho nos Estados Unidos não poderia ser semelhante ao processo de descolonização nos países da África e da Ásia, e o resultado final - como já sabemos hoje - foi o multiculturalismo, o reconhecimento das diferenças e ações afirmativas nos Estados Unidos e em alguns países da Europa ocidental. Desde a década de 1990, isto está se difundindo também na América Latina; vários países da região já adotaram cláusulas nas reformas constitucionais que afirmam o caráter multicultural e multiétnico destas sociedades, assinando também convênios internacionais de proteção aos direitos individuais e coletivos de minorias étnicas e raciais.

E foi frequentando o curso dado por Blauner que decidi tomar a questão racial como tema de tese. Era inicialmente um projeto muito ambicioso por comparar a escravidão e as relações raciais no Brasil e nos Estados Unidos. Confrontado com a enorme bibliografia norte-americana sobre escravidão e relações raciais, tive que delimitar o tema e concentrar-me nas relações e desigualdades raciais no Brasil depois da Abolição.

Queria falar um pouco do panorama dos estudos das relações raciais quando comecei a trabalhar na tese que deu lugar ao livro Discriminação e Desigualdades Raciais no Brasil. Os antecedentes mais imediatos eram as pesquisas do chamado Projeto Unesco, composto por vários estudos locais e uns poucos livros que saíram posteriormente aos resultados desse projeto que se desenvolveu no início da década de 1950. 
E quais eram os estudos do Projeto Unesco? Florestan Fernandes e Roger Bastide estudaram São Paulo; Oracy Nogueira escreveu o conhecido Relatório de Itapetininga e, ainda, o célebre artigo sobre preconceito racial de origem e de marca, que saiu em 1954, no qual ele faz uma comparação entre Estados Unidos e América Latina; Costa Pinto, em seu O Negro no Rio de Janeiro, enfatizava que o negro no Brasil tinha feito uma trajetória de escravo para proletário. Charles Wagley coordenou uma equipe de antropólogos da Universidade de Columbia que estudou pequenas localidades na Bahia, em Minas Gerais, e não lembro quais outros casos. O livro de Wagley e colaboradores se chama Raça e Classe no Brasil Rural. Thales de Azevedo, sociólogo, antropólogo baiano, fez um estudo chamado As Elites de Cor, um Estudo de Ascensão Social, focalizando Salvador, Bahia.

Outros estudos posteriores podiam ser contados com os dedos de uma ou duas mãos. Florestan Fernandes, Integração do Negro na Sociedade de Classes, de 1965, e O Negro no Mundo dos Brancos, de 1972; Fernando Henrique Cardoso e Octávio Ianni, Cor e Mobilidade Social em Florianópolis; de Octávio Ianni, Raça e Classes Sociais no Brasil; Carl Degler, um historiador americano, cujo livro foi traduzido como Nem Preto Nem Branco: Escravidão e Relações Raciais no Brasil e nos Estados Unidos; e Thomas Skidmore, Preto no Branco: Raça e Nacionalidade no Pensamento Brasileiro. Isso era mais ou menos tudo o que havia, no início dos anos 1970, disponível sobre relações raciais.

Acho que muitos desses estudos podiam ser divididos entre os que viram os brasileiros negros desfrutando, desde longa data, de uma integração na chamada "democracia racial" do país, ou aqueles em que o destino do negro era mais vagamente, ou mais claramente, vinculado aos setores populares, à classe operária. No primeiro caso, estariam os trabalhos de Wagley e seus colaboradores, e o de Thales de Azevedo, que se orientavam ou estavam bastante influenciados por estudos anteriores de Gilberto Freyre, Frank Tannenbaum e Donald Pearson. No segundo, estariam, claramente, os de Costa Pinto, Octávio Ianni e, em alguma medida, Florestan Fernandes. Esse seria o caso do que se pode chamar de redução classista das relações raciais.

Vou confessar algo que não constitui um bom exemplo para os doutorandos do Iuperj: confesso que demorei cinco anos para concluir a tese, mas em Berkeley não havia uma Capes para forçar os prazos de titulação, como vocês todos bem sabem que ocorre agora no Brasil. 


\section{Carlos Hasenbalg}

Gostaria de fazer um rápido apanhado dos temas que tratei no livro Discriminação e Desigualdades Raciais no Brasil. O foco da pesquisa centrou-se na estratificação racial e nos mecanismos societários que reproduzem as desigualdades raciais. Um ponto central na análise consistiu em desenfatizar o legado do escravismo como explicação das relações raciais contemporâneas e, em vez disso, acentuar o racismo e a discriminação depois da Abolição como as principais causas da subordinação social dos não brancos e seu recrutamento para posições sociais inferiores. A raça como atributo socialmente elaborado é analisada como um critério eficaz dentre os mecanismos que regulam o preenchimento de posições na estrutura de classes e no sistema de estratificação social.

No início do livro, discuti os três paradigmas da relação senhorescravo que encontrei na historiografia norte-americana sobre escravidão daquela época, os anos 1970. Um desses paradigmas, de Stanley Elkins (Slavery, a Problem in American Institutional and Intellectual Life), enfatizava a "dimensão coercitiva" do escravismo. Outro, de Fogel e Engelmann (Time on the Cross, the Economics of American Negro Slavery), historiadores econômicos de Chicago, de formação neoclássica, desenvolveu o que chamei a "dimensão remunerativa" na relação senhorescravo. Por último, a "dimensão moral" era acentuada por Genovese, que usa a ideia de paternalismo. Genovese afirmava que o paternalismo, um pacto moral entre senhor e escravo, interpretado por cada um deles à sua maneira, teria prevalecido no sul americano e no nordeste brasileiro.

Qual era meu ponto? Meu ponto era que a ênfase unilateral no lado coercitivo da relação senhor-escravo levou a conclusões sobre os padrões patológicos de adaptação psicológica e cultural do escravo à servidão, dando lugar a que essas características grupais patológicas fossem frequentemente projetadas em um período pós-Abolição para explicar o mau ajustamento à condição de liberdade. Claro que Elkins não entrou no período pós-Abolição, mas houve muita gente que, se baseando na ideia do escravo zambo, infantilizado, passou a enfatizar as patologias sociais do negro, depois da escravidão, como explicação de sua situação subordinada.

Então, eu concluía que o paradigma remunerativo neoclássico e o paternalista de Genovese levavam em conta a capacidade do escravo para resistir à infantilização e à desumanização.

Outro ponto importante foi discutir a orientação teórica que explica as relações raciais pós-Abolição como uma sobrevivência ou arcaísmo do 
passado escravista com a finalidade de destacar que a perpetuação da estratificação racial depois da Abolição deve ser explicada através dos interesses materiais e simbólicos do grupo branco dominante. Este ponto crítico estava dirigido a Florestan Fernandes, uma figura importantíssima na Sociologia brasileira. Sempre tive o maior respeito por ele como sociólogo, como intelectual e como militante político, mas o que me parecia é que esse diagnóstico do Florestan, explicando as relações raciais pós-Abolição como herança ou arcaísmo do passado, tirava a responsabilidade das gerações contemporâneas. Ou seja, a culpa era colocada no escravismo, nos senhores de escravos e, de alguma forma, esse diagnóstico isentava as gerações pós-escravidão.

Também fiz uma avaliação crítica da perspectiva assimilacionista que postulava uma incompatibilidade entre industrialização e racismo, e que esteve na moda nos anos 1950 e 1960 na Sociologia americana. A ideia era que a industrialização dissolveria os efeitos do fator racial na estruturação das relações sociais. E olhava para os Estados Unidos, nação rica, desenvolvida e muito industrializada, onde a industrialização não tinha tido nenhum dos efeitos propostos por esta teoria. A mesma coisa acontecia com a África do Sul no período do apartheid. O país mais rico e desenvolvido da África não tinha tido essa dissolução do fator racial como estruturante das relações raciais.

Foi um célebre artigo de Herbert Blumer que me apontou para o seguinte: que estas coisas mudam por conta da mobilização política, como foi, no caso dos Estados Unidos, o movimento pelos direitos civis e outros movimentos mais radicais, posteriores. E, sem dúvida, o caso da mobilização do Congresso Nacional Africano e outros grupos negros militantes que conseguiram a transição para o pós-apartheid. Ou seja, não há industrialização que gere esses efeitos fantásticos, mas a mobilização política, e, no caso da África do Sul, a mobilização política interna foi acompanhada de fortes pressões internacionais contra o regime do apartheid.

Outra coisa que fiz foi dar um giro poulantziano e estruturalista para analisar a relação entre raça, classe social e estratificação social. De Poulantzas, utilizei a distinção que fazia entre os aspectos principais e subordinados da reprodução da estrutura de classes sociais. O primeiro, dizia Poulantzas, refere-se à reprodução das posições na estrutura de classes. E o segundo, subordinado, diz respeito à reprodução dos agentes sociais e sua distribuição na estrutura de classes. A raça, então, 


\section{Carlos Hasenbalg}

foi conceitualizada como se relacionando fundamentalmente ao aspecto subordinado da reprodução das classes, ou seja, ao processo de distribuição dos indivíduos nas posições da estrutura de classes e no sistema de estratificação.

Após essas distinções teóricas iniciais, passei a tratar da constituição histórica das desigualdades raciais no Brasil. Analisei primeiro o padrão da distribuição geográfica da população branca e não branca. Como resultado de mais de três séculos de escravidão, no momento da Abolição, em 1888, a grande maioria de negros e mestiços estava concentrada nas regiões mais estagnadas e menos desenvolvidas do país, enquanto a população branca se concentrava, desproporcionalmente, no Sudeste e Sul, mais desenvolvidos. Por outro lado, a política de estímulo e incentivos à imigração europeia até 1930 reforçou ainda mais esse padrão de segregação geográfica dos grupos de cor que já tinha sido condicionado pela escravidão.

A consequente escassez de oportunidades educacionais e econômicas dos não brancos concentrados nas regiões menos desenvolvidas do país foi apontada como uma das principais causas das desigualdades raciais contemporâneas. E este padrão de distribuição geográfica permanece até hoje, como pode ser facilmente verificado nos dados do Instituto Brasileiro de Geografia e Estatística (IBGE).

O passo seguinte foi abordar as consequências da Abolição para os ex-escravos e para as pessoas de cor livres. No Brasil menos desenvolvido, particularmente no Nordeste, onde se concentrava a maioria dos não brancos, os ex-escravos foram assimilados, sem muitas dificuldades, no sistema preexistente de relações de trabalho tradicionais e dependência senhorial. Já no Sudeste e no Sul, a Abolição coincidia com a entrada maciça de imigrantes europeus, e tanto os ex-escravos como as pessoas de cor livres foram inicialmente excluídas da economia em expansão destas regiões. Somente depois de cessar a imigração europeia, em torno de 1930, se acentuou o processo de proletarização e urbanização de negros e mestiços. E uns poucos membros do grupo começaram a ingressar nas fileiras da nova classe média em formação.

Finalmente, trabalhei as relações entre raça, mobilidade social e política. Analisei os diferenciais raciais de mobilidade social devidos à discriminação racial e mecanismos racistas mais abrangentes. Utilizei os dados de um survey que foi feito aqui no Iuperj, coordenado por Amaury de Souza e Peter McDonough, Representação e Desenvolvi- 
mento no Brasil, e esses dados não eram como os que existem hoje no IBGE, não cobriam todo o país. Os dados sugeriam que não só negros e mestiços nascem desproporcionalmente em famílias de baixo estrato social, como também desfrutam de menores oportunidades de mobilidade social ascendente que os brancos da mesma origem social. Em termos de mobilidade social intergeracional, de uma geração para outra, como intrageracional ou mobilidade de carreira, os não brancos sofrem uma desvantagem competitiva em todas as fases de sequência de transmissão de status. E isto foi confirmado em estudos posteriores por Nelson do Valle Silva e também por outros autores que ingressaram neste tema.

Quanto à raça e política, à baixa posição do Brasil na dimensão de antagonismo racial e à desmobilização política do negro até aquele momento, foram atribuídos: a ausência de mercados de trabalho racialmente segmentados, a fragmentação da identidade racial dos não brancos, ou seja, o fato de que aqui existe um continuum de cor, não uma categorização racial dicotômica; os efeitos da ideologia da democracia racial e certos aspectos das condições de vida da população não branca, principalmente a pouca disponibilidade de recursos necessários para haver mobilização política. E, por último, assinalei o persistente caráter autoritário do sistema político brasileiro nos anos 1970. Vários colegas no Iuperj leram e comentaram partes deste trabalho: Edmundo Campos, Elisa Reis, Edson Nunes, Olavo Brasil, Wanderley Guilherme dos Santos. Luiz Henrique Bahia ensinou-me a usar o programa SPSS quando era preciso ir à PUC (Pontifícia Universidade Católica) à noite, ao Rio Data Centro, e se trabalhava com cartões hollerith . Qualquer erro de perfuração no cartão impedia o programa de rodar.

Gostaria de fazer um comentário muito especial sobre Cesar Guimarães, que leu todos os capítulos, o livro inteiro, e reagiu a todos os capítulos. Eu achava que o tinha explorado muito, mas de alguma forma a amizade que tive com ele desde que cheguei, em 1967, ao Brasil atenuava a minha culpa. Penso que o Cesar Guimarães naquela época era menos erudito que atualmente, tinha lido menos livros que os que leu até hoje, mas a sua inteligência era tão aguda como é agora, e muitos dos alunos do Iuperj sabem disso.

No início dos anos 1980, comecei uma parceria intelectual e de pesquisa com Nelson do Valle Silva, e dessa parceria resultaram outros três livros sobre relações raciais, em 1988, em 1992 e em 1999. Neste último tivemos a colaboração de Márcia Lima, que fez o mestrado no Iuperj e 
hoje é professora do Departamento de Sociologia da USP. Ao mesmo tempo, o tema das relações raciais, que ocupou um lugar secundário nas décadas anteriores, foi reinstalando-se no cenário das ciências sociais brasileiras, particularmente na Sociologia e na Demografia. Os economistas foram os últimos a chegar. Na reunião de 1979 da Anpocs, por exemplo, criou-se um GT, um grupo de trabalho, que se chamava Temas e Problemas da População Negra no Brasil.

A tradição de pesquisa, desenvolvida nos últimos 30 anos, dá forte sustentação à ideia de que os brasileiros não brancos estão expostos a desvantagens cumulativas ao longo de todas as fases do ciclo de vida individual. E vocês podem ver as diferenças em todas essas fases: mortalidade infantil, mortalidade de menores de 5 anos; escolarização; ingresso e permanência no mercado de trabalho; distribuição de renda e esperança de vida ao nascer. Em tudo isto serão encontradas fortes disparidades.

Diante de toda esta evidência acumulada nos últimos tempos, o ônus da prova está com aqueles que tentam desfazer o elo causal entre racismo, discriminação e desigualdade racial. Ora, se as desigualdades raciais no Brasil não são produtos de racismo e discriminação, qual é a teoria ou explicação alternativa para dar conta das desigualdades constatadas?

E aqui chego, quase finalizando, a minha retirada do tema racial, que se deu em torno de 1996, 1997. Entre outras razões para essa retirada, posso citar a falta de ideias novas para a pesquisa e um certo cansaço e estresse. Entre 1986 e 1996, trabalhei no Iuperj, mas também fui vicediretor do Centro de Estudos Afro-Asiáticos, onde levantamos a revista Estudos Afro-Asiáticos e, junto com Nelson, formamos um conjunto de jovens pesquisadores que queriam trabalhar no tema das relações raciais. Outra coisa que também contava era a vontade de explorar e pesquisar outros temas; eu tinha sido monotemático durante 25 anos. Nesse momento (1996-1997), houve uma inflexão nas relações raciais no Brasil: deu-se, pela primeira vez, o reconhecimento oficial da existência de racismo no país por parte do presidente Fernando Henrique Cardoso em 1995-1996; foram iniciadas algumas políticas públicas dirigidas aos afro-brasileiros; e teve início o debate, ainda em curso, sobre as políticas de ação afirmativa.

Minha ruptura com o tema se concretizou através de uma pesquisa sobre imigrantes brasileiros na Argentina, que fiz junto com Alejandro 
Frigerio, um antropólogo argentino. O projeto teve patrocínio da Fundação Centro de Estudos Brasileiros (Funceb), de Buenos Aires, então dirigida por Mônica Hirst.

Os meus devaneios sociológicos nesta Instituição terminaram com o Instituto Virtual da Fundação Carlos Chagas Filho de Amparo à Pesquisa do Estado do Rio de Janeiro - Faperj/Iuperj, chamado O Estado Social da Nação, Brasil e Rio de Janeiro, que coordenei junto com Nelson do Valle e que deu lugar ao livro Origens e Destinos, Desigualdades Sociais ao Longo da Vida. Essa pesquisa consistiu na implementação do esquema analítico de uma disciplina chamada Desigualdades Sociais, que nós vínhamos oferecendo, aqui no Iuperj, por pelo menos 10 anos.

Com a saída deste Instituto Virtual, finalmente, pudemos transformar o que era um curso ou uma disciplina no Iuperj em uma pesquisa. Contamos com a colaboração de vários colegas que redigiram alguns dos capítulos. E o que aconteceu? Como é impossível tratar das desigualdades sociais no Brasil sem que o tema racial reapareça, ele voltou a aflorar em praticamente todos os capítulos de Origens e Destinos...

Em janeiro de 2006, fiz as malas e voltei para "mi Buenos Aires querido". Lá aparecem, com alguma frequência, colegas e amigos, não sabendo eu se por amizade ou se porque Argentina e Buenos Aires estão muito baratos para os brasileiros. Parece que Buenos Aires voltou a ser a Paris da América Latina, em versão econômica. Muito obrigado a todos vocês. 


\section{Carlos Hasenbalg}

\section{RESUMO}

Privilégios: Relato de uma Trajetória Acadêmica

Este texto corresponde à Aula Magna proferida por Carlos Hasenbalg no dia 21 de maio de 2007 no antigo Instituto Universitário de Pesquisas do Rio de Janeiro (Iuperj), atual Instituto de Estudos Sociais e Políticos da Universidade do Estado do Rio de Janeiro (IESP-UERJ), um ano após ter deixado o Instituto para retornar à sua cidade natal, Buenos Aires, onde faleceu no dia 5 de outubro de 2014. O autor narra sua formação e trajetória intelectual, bem como a construção do campo de estudos sobre relações e desigualdades raciais no Brasil.

Palavras-chave: Carlos Hasenbalg; trajetória intelectual; relações raciais; desigualdades raciais; racismo

\section{ABSTRACT}

\section{Privilege: The Summing Up of an Academic Career}

This text is the transcription of the Master Class proffered by Professor Carlos Hasenbalg on May 21, 2007 at the former University Research Institute of Rio de Janeiro (Iuperj), currently Institute of Social and Political Studies - State University of Rio de Janeiro (IESP-UERJ), a year after leaving the institute to return to his home city of Buenos Aires, where he passed away on October 5, 2014. The author narrates his formative years and intellectual trajectory, as well as the establishment of the academic field of racial relations and inequalities in Brazil.

Keywords: Carlos Hasenbalg; intellectual trajectory; racial relations; racial inequality; racism

\section{RÉSUMÉ}

\section{Privilèges: Récit d'une Carrière Académique}

Ce texte correspond à la Conference prononcée par Carlos Hasenbalg le 21 mai 2007 à l'ancien Institut de Recherche de Rio de Janeiro (Iuperj), actuel Institut d'Études Sociales et Politiques de l'Université de l'État de Rio de Janeiro (IESP-UERJ), un an après avoir quitté l'institut pour retourner à sa ville natale Buenos Aires, où il est décédé le 5 octobre 2014. L'auteur décrit sa formation et carrière intellectuelle, ainsi que la construction du domaine d'études sur les relations et inégalités raciales au Brésil.

Mots-clés: Carlos Hasenbalg; carrière intellectuelle; relations raciales; inégalités raciales; racisme 


\section{RESUMEN}

Privilegios: Relato de una Trayectoria Académica

Este texto corresponde a la Conferencia Magistral proferida por Carlos Hasenbalg el día 21 de mayo de 2007 en el antiguo Instituto Universitario de Investigaciones de Río de Janeiro (Iuperj), actual Instituto de Estudios Sociales y Políticos de la Universidad Estatal de Río de Janeiro (IESP-UERJ), un año después de haber dejado el instituto para regresar a su ciudad natal, Buenos Aires, donde falleció el día 5 de octubre de 2014. El autor narra su formación y trayectoria intelectual, bien como la construcción del campo de estudios sobre relaciones y desigualdades raciales en Brasil.

Palabras clave: Carlos Hasenbalg; trayectoria intelectual; relaciones raciales; desigualdades raciales; racismo 